\title{
"CUIDANDO DIEGO LAÍNEZ..." YLA FUNCIÓN DE LA HIPÓTESIS DE TRABAJO EN ECDÓTICA ${ }^{1}$
}

\section{LA HIPÓTESIS DE TRABAJO}

En otra parte tuve ya la oportunidad de señalar algunas de las virtudes que había que conceder al concepto de hipótesis de trabajo en ecdótica, más allá de ese tratamiento culposo en el que se limita su uso a la fase hipotética del trabajo editorial, la emendatio ${ }^{2}$. Decía entonces que resultaría más provechoso considerarlo como un concepto aplicable a todas las fases del trabajo ecdótico $\mathrm{y}$, especialmente, a aquellas vinculadas a la toma de decisiones que terminaría por configurar un texto crítico. Así, al entender la hipótesis de trabajo como el "sistema complejo

I Vayan en esta nota mis agradecimientos a varios colegas y amigos que han colaborado de muy distintas maneras para la realización de este proyecto. Por principio, a Antonio Carreira que, apasionado como es de la perfección y el Romancero nuevo, contribuyó al desarrollo de este trabajo con observaciones oportunas sobre el valor de las variantes y la pesquisa de algunos testimonios que no había considerado o no había podido conseguir al momento de redactar la primera versión del presente texto. A Ralph DiFranco, por su buena disposición para hacerme llegar un ejemplar del Romancero de Palacio, recientemente publicado en la cada vez más imprescindible colección de Cancioneros Castellanos. La obtención de un microfilme del ejemplar de 1605 del Romancero de Juan de Escobar fue posible gracias a la generosa y desinteresada labor de Susan Artebi, quien localizó el ejemplar para mí, y a la amable gestión de Tom Ford, del Reading Room de la Houghton Library. A Fernando Gomarín, quien por intercesión de Antonio Carreira me envió amable y oportunamente fotocopias del ejemplar de la Noven a flor de romances conservado en la Biblioteca Menéndez Pelayo. De los errores, por supuesto, el único responsable soy yo.

2 Véase mi artículo, "La edición crítica como hipótesis de trabajo", en Filología mexicana, coords. B. Clark de Lara y F. Curiel Defossé, UNAM, México, 2001, pp. 533-549. 
de decisiones, apoyadas en evidencia empírica y en suposiciones, que explica la génesis y transmisión de una obra”, el editor estaría obligado a tener en mente a lo largo de todo el proceso editorial el hecho de que "cada decisión tomada entra en una relación de equilibrio con todas las otras decisiones"3. Esto, sin perder de vista que una parte importante de estas decisiones estaría basada en fenómenos concretos observables en los testimonios, mientras que otra habría de ser deducida racionalmente a partir de un estudio cuidadoso del comportamiento de estos mismos testimonios.

Esta definición, primordialmente ensayada contra la idea que limita la hipótesis de trabajo al ámbito de las conjeturas, permitía también superar decisiones mecánicas basadas en criterios, paradójicamente acríticos, del tipo "se restituye el valor vocálico o consonántico de las distintas realizaciones gráficas de $\mathrm{i} / \mathrm{j} / \mathrm{y}$ según su uso moderno", "se acentúa según el uso moderno", "se puntúa según el uso moderno", etc. ${ }^{4}$ Ante el concepto de hipótesis de trabajo, el editor está obligado a valorar el impacto de sus decisiones en el contexto más amplio del propio texto crítico. Si dentro de la hipótesis se considera la transmisión oral de la obra que se edita (sermones, crónicas, libros de caballerías, etc.), por ejemplo, la puntuación tendrá que respetar lo que Germán Orduna llamó tan atinadamente la "textualidad oral del discurso narrativo" 5 . Con ello, la interpunción no podrá ser "según el uso moderno", sino siguiendo y respetando los largos períodos medievales y un sistema expletivo de nexos introductorios que el español escrito actual abandonó hace tiempo; la diuisio textus editorial tenderá, consecuentemente, al párrafo amplio.

En esta ocasión, quisiera volver sobre el modo en el que una hipótesis de trabajo coherentemente formulada puede ayudar

${ }^{3}$ Ibid., pp. 537-538.

${ }^{4}$ Ibid., pp. 546-548.

${ }^{5}$ En uno de sus últimos estudios al respecto, antes de partir, apuntaba Germán Orduna que "es en la elocución oral donde el período adquiere sentido" y donde "ciertos conectores -sobre todo nexos introductorios expletivos, que sugieren, en la lectura silenciosa una deturpación del texto-, adquieren un sentido, y los giros, aparentemente deturpados, logran su entidad significativa al vincularse, por la curva melódica, a la estructura sintáctica con que el período había sido construido" "La textualidad oral del discurso narrativo en España e Hispanoamérica [ss. XIV-Xur]]", en Estudios sobre la variación textual. Prosa castellana de los siglos XnI al XVI, de G. Orduna et al, Seminario de Edición y Crítica Textual-Incipit Publicaciones, Buenos Aires, 2001, p. 1). 
a la penosa tarea de tomar decisiones críticas en el proceso de edición. El siguiente ejemplo está tomado de un proyecto personal de largo aliento, la edición crítica de los romances incluidos en el Romancero e historia del muy valeroso caballero el Cid Ruy Díaz de Vivar (Alcalá, 1612). Las peculiaridades del trabajo que emprendí hace algunos años (y que tardaré algunos tantos más en terminar) no escapan al lector: se trata de uno de esos casos límite de la ecdótica en los que el editor difícilmente puede concebir la existencia de un "original" o un mejor estado del texto $^{6}$, pues a menudo cada versión apunta hacia un estado de variación de la obra válido en sí mismo desde la perspectiva de los transmisores (y, debemos suponer, también desde la perspectiva de los lectores). Esto, que podría parecer la conclusión de un estudio sobre la variación en el Romancero, es en realidad la hipótesis de trabajo que sostiene y articula muchas de las decisiones sobre la edición del corpus.

\section{RECENSIO}

En principio, estos estados de variación deberían estar bien ilustrados por los resultados de la recensio de los testimonios previos a su recuperación en el Romancero e historia, como en efecto lo están. Aunque en esta primera fase del trabajo ecdótico las variantes sólo son pertinentes para la filiación de los testimonios, en la collatio codicum es posible advertir que resulta difícil preferir la lección de un testimonio o de una familia sobre la de otro y otra (por más que sirvan para la filiación). La propia fase correspondiente a las fontes criticae ilustra ya esta rica variación por la heterogeneidad de las fuentes que deben considerarse y que van, desde manuscritos y pliegos sueltos, hasta colecciones de romances y romanceros propiamente temáticos, como el de Juan de Escobar. Así, en el caso del Romance I del Romancero e historia del Cid ("Cuidando Diego Laínez..."), los testimonios conservados previos a su inclusión en la copilación de Juan de Escobar son los siguientes:

6 Véase Germán Orduna, Ecdótica, problemática de la edición de textos, Reichenberger, Kassel, 2000, pp. 173-174. 
MANUSCRITOS

$m p$ Real Biblioteca (Madrid), ms. 11-996.

Romancero de Palacio, ff. 191r-191v7.

\section{Pliegos sueltos}

$P \quad$ SEXto QVa $\mid$ DeRno de VA- $\mid$ rios Romances. $\mid 1$. Non me culpedes si he fecho. |2. Cuydando Diego Laynes. |3. A mi patron. |4. Ventezillo murmurador. 5. Romance a los adorantes. |6. Ques esto pensamiento. | [Dos grabados: tocador de guitarra, dama] | Impresso en Valencia, junto al molino | de la Rouella, Año 1595. | Vendense en la calle de los flaçaderos, |junto a la Merced.

Pliego suelto en la Biblioteca Universitaria de Pisa, $15^{8}$.

$M$ Aquise contien en seys Romãces | del Cid Ruydiaz de Viuar, E1 primero cuydando Diego Lay | ney El segundo, Consolando al noble viejo. El tercero en los $\mid$ solares de Burgos. El quarto Pidiendo a las diez del | dia. El quinto Vitorioso buelue el Cid. El sexto | E1 vasallo desleal. Aora nueua | mente impresos con Licencia.

Pliego suelto de la colección Morbecq, $29^{9}$.

\section{ROMANCEROS}

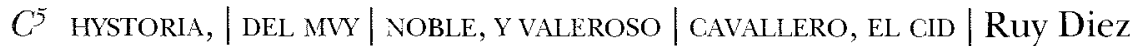
de Biuar: En Roman- | ces: En lenguaje | antiguo. | RECopilados POR | luan de Escobar. | [hoja única vertical que apunta al marco] DIRIGIDA A DON [hoja única vertical que apunta al marco] |Rodrigo de Valençuela, Regi- | dor de la Ciudad de | Andujar. | [hoja única vertical que apunta al marco] EN LISBOA. [hoja única vertical que apunta al marco] | Impressa con licencia de la Sancta In- | quisicion:

${ }^{7}$ Romancero de Palacio (siglo Xu), eds. J. J. Labrador Herraiz, R. A. DiFranco y L. A. Bernard; pról. J. Fennández Jiménez, Cleveland State UniversityUniversity of Denver, Cleveland, 1999, pp. 208-209.

${ }^{8}$ Pliegos poéticos españoles de la Biblioteca Universitaria de Pisa, ed. en facs. precedida de una introd. de G. di Stefano y un est. de M. Cruz García de Enterría, Joyas Bibliográficas, Madrid, 1974, pp. 219-220.

9 Antonio Rodríguez-Moñino, Los pliegos poéticos de la colección del marqués de Morbecq (siglo xi7), Estudios Bibliográficos, Madrid, 1962, pp. 319-320. 
Por Antonio Aluarez. | Anno M. Ccccccv | [ raya]

Portada enmarcada, laterales y superior, por tres versos entre adornos verticales en forma de hojas de acanto que apuntan hacia el exterior de los textos: Soy el Cid honra de España, / Si alguno pudo ser mas, / En mis obras lo veras.

Harvard College Library, Houghton Library 26252.14.5.

$C^{12}$ ROMANCERO. | E HISTORIA | DEL MUY VALERo- | SO CAVALLERO EL CID | Ruy Diaz de Biuar, en lenguage anti- | guo. Recopilado por luan | de Escobar. | Dirigido a dõ Rodrigo de Valençuela, Re- | gidor de la Ciudad de Anduxar. | [grabado grande, jinete con lanza] | CON LICENCIA. | En Alcala, en casa de luan Gracian, que sea | en gloria, Año 1612.

BNMadrid R-31248

$F^{91}$ FLOR DE | varios Romances, dife- | rentes de todos los | impressos. | nOVEna PARTe. | [Dos grabados: galán, galán] | EN MADRID, | Por luan Flamenco. | raya] | M. D. XCVir.

Fuentes del Romancero general, XI ${ }^{10}$.

F92 NOVENA | PARTE DE | flor de varios Romances, dif $\mid$ ferentes de todos los | impressos. | va AÑADIDO. | [Dos grabados: dama con la palabra amor, galán] | En Alcala de Henares. En | casa de luan Gracian | que sea engloria. | Año 1600.

Biblioteca Menéndez Pelayo (Santander), núm. 129.

$G^{I}$ ROMANCERO GE- $\mid$ NERAL, EN QVE SE CON- | tienen todos los Romances que andan | impressos en las nueue partes | de Romanceros. | AORA NVEVAMENTE | impresso, añadido, y emendado | Año [Escudo con la leyenda: CAELESTIS ORIgo] 1600 | Con licencia, En Madrid, Por Luis Sanchez. | A costa de Miguel Martinez.

BNMadrid R-13740.

$G^{2}$ ROMANCERO GE- | NERAL, EN QVE SE CONTIE- $\mid$ nen todos los Romances que andan impres- | sos en las nueue partes de Ro- | manceros. | AORA NVEVAMENTE | impresso, añadido, y emendado| [Halcón y mano de halconero con la leyenda: SPERO LUCEM POST TENEBRAS] | Con licencia,

${ }^{10}$ Las fuentes del Romancero general (Madrid, 1600), Flor de varios romances novena parte, hecha imprimir por Luis de Medina (Madrid, 1597), ed., notas e indices de A. Rodríguez-Moñino, Real Academia Española, Madrid, 1957. 
En Medina del Campo, Por Iuan Go- I dinez de Millis. I A costa de Pedro Ossete y Antonio Cuello libreros de Valladolid. | Año 1602.

BNMadrid USOZ-255.

$G^{3}$ Romancero | GeNeral, EN | QVE SE CONTIENEN todos | Los Romances que andan impressos. | AORA NVEVAMENTE | añadido, y enmendado. Año [Grabado: halcón y mano de halconero con la leyenda SPERO LUCEM POST TENEBRAs] 1604 | CON Licencia. | En Madrid, por luan de la Cuesta. | [raya] |Vendese en casa de Francisco Lopez.

BNMadrid R-10952.

La recensio de dichos testimonios arroja los siguientes resultados ${ }^{11}: G^{3}<G^{2}$ son codices descripti de $G^{1}$ como cabría suponer. Las variantes que presentan entre sí son atribuibles a variantes espontáneas de los transmisores:

40 piensa $G^{1} G^{2}$ piensan $G^{3}$

44 la faz $G^{I}$ a faz $G^{2} G^{3}$

45 en mal hora $G^{1} G^{2}$ mal hora $G^{3}$

Aunque a veces, podría tratarse claramente de enmiendas por contaminación, como en los casos en que $G^{3}$ reproduce lecciones de $G^{l}$ sin pasar por $G^{2}$, en ciertos loci que el editor del Romancero general de 1604 consideró que podían corregirse o mejorarse recurriendo a las lecciones primigenias de 1600:

3 rica $C^{I} G^{3}$ noble $G^{2}$

10 gustar $G^{1} G^{3}$ gastar $G^{2}$

56-57 firmeza $G^{1} G^{3}$ fiereza $G^{2}$

Las variantes conjuntivas que filian la familia de $G$ (correspondiente a $G^{1}$ y sus descripti) con $P$ también son numerosas, lo que permite deducir que $P$ sirvió de fuente para la versión del romance incorporada al Romancero general. Aunque las fuentes aceptadas para el Romancero general se han limitado tradicionalmente a las Flores de Romances, "Cuidando Diego Laínez..." es

${ }^{11}$ Véase en apéndice el texto crítico, el aparato crítico y el stemma codicum de este romance. Los números de las variantes corresponden a la numeración de versos en el texto editado. 
un buen ejemplo de casos en los que la advertencia de "añadido, y emendado" de la edición de 1600 debe hacerse valer: intentando ir más allá de la mera fuente que sirve de base a la nueva copilación, el editor se remonta hasta un pliego suelto de 1595 y cuya autoridad, en vista de su factura más antigua, parece indiscutible. Esto es lo que permiten deducir las numerosas lectiones compartidas (y que pueden considerarse extravagantes si se comparan con el resto de la tradición):

4 Íñigo Abarca $C^{12}$ Yñigo, y Abarca $C^{5}$ Nuño y Abarca $F 9^{1} F{ }^{92}$ Iñigo de Abarca $m p$ Yñigio Abarca $M$ Ynigo y Abarca $P G$

13 nin fablar $F 9^{1} F 9^{2} C^{5} C^{12}$ ni fablar $m p M$ Nin fabla $P G$

23 les fue apretando una a una $C^{5} C^{12}$ les fue apretando vno a vno $F 9^{7} F^{92} m p$ les aprieta vno auno $M$ les apretara vno a vno $P G$

27 que este $F{ }^{1} F 9^{2} C^{5} C^{12} m p$ que aqueste $M$ que aquel $P G$

46 soltedes en hora mala $C^{5} C^{12} M$ solteys muy en hora mala F9l F92 $m p$ solteis \{soltes $P$ \} padre en hora mala $P G$

48 de palabras $C^{5} C^{12}$ con palabras $F^{91} F 9^{2} m p$ de palabra $M$ con palabra $P G$

58 muéstralos en la demanda $C^{5} C^{12} m p$ teneldos en la vengança $F 9^{1} F 9^{2}$ mostraldos en la vengança $M$ muestralos en la vengança $P G$

Las variantes separativas que pueden encontrarse entre $P y$ la familia $G$ no representan un estado de variación importante y son, en la mayor parte de los casos, reconstrucciones que se apartan apenas perceptiblemente del modelo (muchas veces, exclusivamente en aspectos gráficos):

8-9 loçano en nombre y en gala $P$ loçano en el nombre, y gala $G$

19 esperiencia $P$ experiencia $G$

25 Non $P$ No $G$ l en ello $P$ en ellos $G$

56 indignacion $P$ indinacion $G$

$60 \sin$ ti $P$ sienti $G$

A la luz de dichas variantes separativas, puede considerase con relativa certeza una filiación sin intermediarios. Esto, al menos, por lo que toca al stemma, pues siempre es posible la existencia de algún testimonio intermedio, derivado de $P$ o con una posición superior en el stemma (como modelo de $P$ ), no conservado. 
Las variantes conjuntivas que comparten $M$ y $P G$ sugieren la presencia de un ascendiente común $\beta$ (del que $P$ bien podría representar un primer testimonio por su datación) y su clara oposición con la otra rama del stemma, $\alpha$ :

2 en la mengua $F^{91} F{ }^{92} C^{5} C^{\prime 2} m p$ por las menguas $P G^{l} G^{2} G^{3} M$

12 de su casa $F^{91} F 9^{2} C^{5} C^{12} m p$ de la sala $P G^{1} G^{2} G^{3} M$

28 no era nacido $F^{91} F^{92} C^{5} C^{12} m p$ no auia nacido $P G^{1} C^{2} G^{3} M$

29 Mas prestando al honor fuerças $C^{5} C^{12} \mathrm{Y}$ prestando el honor fuerças $F 9^{1} F 9^{2} \mathrm{Y}$ poniendo fpuniendo $P$ \} al honor fuerça $P G^{1} G^{2} G^{3} M$

43 con mucha furia $C^{5} C^{12}$ con tanta yra $F^{91} F^{2}$ con tal semblante $P G^{1} G^{2} G^{3} M$

49 con la mano mesma $\left\{\right.$ misma $\left.F{ }^{91} F 9^{2} C^{5} m p\right\} F^{91} F 9^{2} C^{5} C^{12} m p$ con mis propias manos $P G^{1} G^{2} G^{3} M$

53 Llorando de gozo el viejo $F^{91} F^{92} C^{5} C^{12} m p$ El padre llora de gozo $P G^{1} G^{2} G^{3} M$

63 dio al Conde la muerte $F^{91} F^{92} C^{5} C^{12} m p$ dio la muerte al Conde $P G^{l} G^{2} G^{3} M$

Esto, por supuesto, sin contar la omisión de $F^{91} F^{2} C^{5} C^{12} \mathrm{mp}$ entre los versos 56-57, cuarteta añadida en $P G^{1} G^{2} G^{3} M$ (como se verá) y que resulta una prueba definitiva para dividir el stemma en dos ramas.

$M$ se separa de $P G$, sin embargo, por otras tantas numerosas lecciones singulares que apuntan a una reproducción innovadora a partir de alguno de los miembros de la familia $\beta$, sin que sea posible identificar un modelo específico. Dentro de estas lecciones innovadoras se han colado, por lo menos en un par de ocasiones, errores de lectura como 16 (trastrocando "el aliento de su infamia" por "el asiento de su infamia") o métricos como 42 (verso hipométrico, salvo una lectura extravagante como "Hircanía"), lo que nos habla de una versión descuidada:

4 Yñigio Abarca $M$ Ynigo y Abarca $P G$

12 no osa $M$ ni osa $P G$

13 ni fablar $M$ Nin fabla $P G$ 
16 el asiento $M$ el aliento cett.

21 sus tres hijos $M$ sus tres fijos $P G$

23 les aprieta vno auno $M$ les apretara vno a vno $P G$

27 que aqueste $M$ que aquel $P G$

42 qual Tiger de Hircania $M$ qual fiera tigre de Hircania $P G$

48 de palabra $M$ con palabra $P G$

54 Hijo $M$ Fijo $P G$

58 mostraldos en la vengança $M$ muestralos en la vengança $P G$

64 azañas $M$ fazañas $P G$

Por razones cronológicas, la posición inferior de la otra rama importante del stemma corresponde a $C$. La relación $C^{12}<$ $C^{5}<F 9^{2}<F 9^{l}$ no está, creo, sujeta a discusión: son numerosos los casos en que $C^{12}<C^{5}$ conserva las lecciones singulares de $F 9$ (todas aquellas variantes conjuntivas que ijustifican $\beta$, esto es, $P G M$, con ejemplos importantes como la omisión entre los vv. 56-57 que ya hemos notado). Las ocasiones en que $C$ se separa de las lecciones particulares de $F 9$ pueden atribuirse a la intervención de Juan de Escobar, según distintos criterios:

a) Variantes adiáforas, generalmente como una forma de mejoramiento estilístico sin modificaciones importantes dentro del sentido de la frase, del tipo:

19 quiso hazer cierta esperiencia $F^{91} F^{92}$ para usar de una esperiencia $C^{5} C^{12}$

23 les fue apretando vno a vno $F^{91} F^{92}$ les fue apretando una a una $C^{5} C^{12}$

29 Y prestando el honor fuerças $F 9^{l} F 9^{2}$ Mas prestando al honor fuerças $C^{5} C^{12}$

42 qual fiera tigre de Yrcania $F{ }^{l} F 9^{2}$ cual furiosa tigre Ircana $C^{5} C^{12}$

46 solteys muy en hora mala $F^{91} F^{2}$ soltedes en hora mala $C^{5} C^{12}$

48 con palabras $F^{91} F 9^{2}$ de palabras $C^{5} C^{12}$

$51 \mathrm{mi}$ dedo $F^{91} F 9^{2}$ el dedo $C^{5} C^{12}$

60 si en vos $F^{91} F^{92}$ si en ti $C^{5} C^{12}$ 
b) Regularizaciones gráficas poligenéticas, poco impor tantes siempre que no impactan en la res metrica:

9 Non puede $F 9^{1} F 9^{2}$ no puede $C^{5} C^{12}$

25 Non $F^{91} F 9^{2}$ No $C^{5} C^{12}$

64 hazañas $F 9^{1} F 9^{2}$ fazañas $C^{5} C^{12}$

c) Omisiones de cuartetas, como:

8-9 Y que el de Orgaz se pasea / libre y esento \{seguro y libre $F 9 m p$ \} en la plaça, / sin que nadie $\{$ sin aber quien $m p\}$ se lo impida / lozano en el nombre y gala \{loçano en nombre y en gala \{galas $m p\} F 9 m p P\}$ om. $C$

44-45 Sacando [Sacò $F 9$ hechó $m p$ ] atras el pie izquierdo / la mano diestra sacara $\{y$ la diestra mano saca $F 9 \mathrm{mp}\}$ / y al viejo padre le dize $\{y$ buelto a su padre dize $F 9 m p\}$ / que asaz \{la faz $G^{l}$ a faz $\left.F 9 G^{2} G^{3}\right]$ mirando le estaua \{que en esta guisa miraba $\mathrm{mp}$ o om. $C$

d) Correcciones ope ingenii con el propósito de aclarar una lección cuyo sentido pudo resultar poco transparente, como:

57 Essos fieros $F^{91} F^{92}$ Essos braços $C^{5}$ Estos braços $C^{12}$

e) $\mathrm{Y}$, sin absoluta seguridad, a correcciones ope codicum:

4 Nuño y Abarca $F 9^{1} F 9^{2}$ Yñigo, y Abarca $C^{5}$ Íñigo Abarca $C^{12}$ [que pudo haberse corregido sobre la lección de $P G$, Ynigo y Abarca]

54 dize $F^{91} F^{2}$ dixo $C^{5} C^{12}$ [donde la familia de $C$ podría seguir a $\left.G^{1} G^{2} G^{3}\right]$

58 teneldos en la vengança $F{ }^{1} F 9^{2}$ muéstralos en la demanda $C^{5} C^{12}$ [donde la familia de $C$ sigue de cerca la lección de $P G$, muestralos en la vengança]

En este último caso es evidente que, de tratarse de verdaderas correcciones ope codicum, estaríamos obligados a considerar algunas contaminaciones entre $C$ y $P G$, lo cual no sería de extrañar si tenemos en cuenta el enorme éxito que tuvo el Romancero general de 1600 y sus reediciones de 1602-1604. Aunque en muchos casos podría tratarse exclusivamente de variantes poligenéticas, debe considerarse una alta probabilidad para la contaminación entre estos testimonios a la luz de los casos 
anteriores, ya sea por el conocimiento del propio testimonio impreso, ya sea por el conocimiento de la versión oral circulante emanada de la familia.

Lo mismo puede decirse de otras posibles contaminaciones que se advierten al revisar el aparato de variantes (por ejemplo, $C^{12}<C^{5}$ con $M$ en el v. 46); la posibilidad de contaminación, sin embargo, no puede pasar en estos casos del terreno de la hipótesis y muy probablemente de la variante poligenética; esto, sin perder de vista que la transmisión oral y tradicionalizada de los textos obliga también a considerar la posibilidad de innovaciones en los textos procedentes del recuerdo del copilador, del cajista o de cualquier otra persona involucrada en el proceso editorial.

La complejidad de este proceso tiene particular relevancia para la colocación dentro del stemma del manuscrito $m p$. Si revisamos su posición, rápidamente se puede constatar su pertenencia a la familia $\alpha$ (véanse los ejemplos separativos correspondientes supra). Nuestras certezas, por desgracia, no pueden ir más allá de este señalamiento, pues son numerosas las lecturas que comparte tanto con los testimonios del Romancero historiado del Cid como con los de Flores.

a) Variantes conjuntivas que filian $C y$ y $m$ :

15 que les ofenda $C m p$ no les ofenda cett.

21 a sus hijos $C m p$ sus tres fijos F9PG sus tres hijos $M$

22 dezirles $\mathrm{Cmp}$ fablalles cett.

36 Suéltanos Cmp dexanos cett.

40 que a do no piensa $C m p$ que do no piensan $F 9 P G^{1} G^{2} M$ que do no piensa $G^{3}$

58 muéstralos en la demanda $C m p$ teneldos en la vengança $F 9$ mostraldos en la vengança $M$ muestralos en la vengança $P G$

60 si en ti $C m p G M$ si en vos $F 9 \sin$ ti $P \mid$ cobra y cett. cobra, o $C^{5} \mid$ gana $C m p$ halla cett.

b) Variantes conjuntivas que filian $F 9$ y $m p$ :

8-9 Y que el de Orgaz se pasea / libre y esento \{seguro y libre $F 9 m p\}$ en la plaça, / sin que nadie $\{$ sin aber quien $m p\}$ se lo impida / lozano en el nombre y gala \{loçano en nombre y en gala \{galas $m p\} F 9 m p P\}$ om. $C$ 
23 les fue apretando vno a vno $F 9 m p$ les fue aprentando una a una $C$ les apretara vno a vno $P G$ les aprieta vno auno $M$

44-45 Sacando \{Sacò $F 9$ hechó $m p$ \} atras el pie izquierdo / la mano diestra sacara $\{y$ la diestra mano saca $F 9 \mathrm{mp}\}$ / y al viejo padre le dize $\{$ y buelto a su padre dize $F 9 m p\}$ / que asaz $\left\{\right.$ la faz $G^{1}$ a faz $\left.F 9 G^{2} G^{3}\right\}$ mirando le estaua \{que en esta guisa miraba $m p$ om. $C$

46 solteys muy en hora mala $F 9 m p$ soltedes en hora mala $C M$ solteis $\{$ soltes $P\}$ padre en hora mala $P G$

48 con palabras $F 9 m p$ de palabras $C$ de palabra $M$ con palabra $P G$ 51 mi dedo $F 9 m p$ el dedo $C$ mi braço $\beta$

La conducta de $m p$ dentro del stemma expresa los problemas a los que se enfrenta el editor que intenta desbrozar la tradición de un texto que, culto en su origen y escrito en las coordenadas estéticas del Romancero nuevo, tiende a transmitirse de acuerdo con las costumbres que privan en los canales tradicionales, contaminando a voluntad distintas lecciones que proceden de un recuerdo oral de diversas versiones o de la consulta de los distintos impresos asequibles, pero sin responder propiamente a una voluntad de fidelidad a alguno de los testimonios en un espacio textual donde ninguno de ellos parece dominar por la calidad de sus lecciones para el copista de $m p$, como un "mejor testimonio" cuyas lecciones valga la pena conservar. Por el contrario, podemos ver que en $m p$ incluso convergen lecciones totalmente inesperadas de la rama $\beta$ (especialmente, bajo el tutelaje de $M$ ):

13 ni fablar $m p M$ min fablar $F 9 C$ Nin fabla $P G$

25 No mpMC 12 Non F9C $P G$

54 Hijo mpM Fijo cett.

57 Esos brios $\beta m p$ Essos fieros $F 9$ Essos braços $C^{5}$ Estos braços $C^{12}$

Aunque en casos como 13,25 y 54 claramente puede tratarse de variantes poligenéticas, conviene considerar el caso del v. 57, confeccionado de acuerdo con la lección de la rama $\beta$ y que muy difícilmente podría considerarse como una lección poligenética (pensando en que la justificación para "essos bríos", como veremos más adelante, sería evitar la repetición de "essa fiereza" con que inicia la cuarteta agregada exclusivamente en la rama $\beta$ y que en $\alpha$ no tiene ninguna justificación). 
Esto, sin olvidar por supuesto la presencia de numerosas lecciones innovadoras y omisiones de cuartetas dentro del manuscrito que la tradición impresa desconoce:

4 Iñigo de Abarca $m p$ Íñigo Abarca $C^{12}$ Yñigo, y Abarca $C^{5}$ Nuño y Abarca $F 9$ Ynigo y Abarca $P G$ Yñigio Abarca $M$

5 la fallecen $m p$ le fallecen cett.

19 para haçer cierta esperiençia $m p$ para usar de una esperiencia $C$ quiso hazer cierta esperiencia $F 9$ quiso hazer vna esperiencia \{ispirencia $M$ experiencia $G\} \beta$

24 sus $m p$ las $c e t t$.

29-32 om. mp

33 Y apretóles de manera $m p$ les apretó de manera cett.

34 Señó $m p$ Señor $c e t t$.

41-44 om. mp

50 os $m p$ vos cett.

51 hiçiendo $m p$ faziendo cett.

54 díjole $m p$ dixo $C G$ dize $F 9 P M$

56 alteraçión $m p$ indinación $C^{12} G M$ indignacion $C^{5} F 9 P$

59 de mi honrra ques perdida $m p$ de mi honor que está perdido cett.

61 el agrabio $m p$ su agravio cett.

62 su espada $m p$ el espada $P$ la espada cett.

\section{Hipótesis DE TRABAJO Y CONSTITUTIO TEXTUS}

Hasta aquí parece claro que una hipótesis de trabajo consistente será aquella que se proponga la representación económica y orgánica de la tradición impresa de este Romancero y de cada uno de los romances que componen la copilación de Juan de Escobar en su individualidad. Todo ello, por medio de un texto crítico que corresponda a un testimonio de referencia -es decir, a un testimonio privilegiado por razones extrínsecas que no siempre dependen de razones ecdóticas, sino a una selección arbitraria por parte del editor-, y el aparato de variantes, 
más que a variantes eliminadas, a un aparato que dé cuenta puntual del texto en su diacronía. En el caso del texto editado dentro del apéndice final, no elijo el testimonio de la rama $\alpha$ por sus "mejores" o "peores" lecciones, como se verá, sino porque es ésa la rama de la que depende la familia del Romancero $e$ historia del Cid de Juan de Escobar en el caso específico de "Cuidando Diego Laínez..." y representa el camino más directo para llegar al testimonio de referencia que se edita (el de Alcalá, 1612); testimonio que da cuenta, por otro lado, de la primera edición conocida de la versión más completa del Romancero $e$ historia del Cid y es punto de partida para un buen número de las ediciones posteriores ${ }^{12}$. La naturaleza de la copilación, por otro lado, obliga también a partir del Romancero e historia del Cid de Juan de Escobar; aunque no conocemos nada más de su autor que el nombre y el producto de su esfuerzo para reunir y articular esta colección de romances, se trata de uno de los muchos estados textuales en el que los lectores de su momento conocieron la copilación, pero que sin duda triunfaría con los años como Romancero cidiano. Por más que la calidad de los resultados finales parezca dudosa, en el orden estético e ideológico ${ }^{13}$, se trata de una versión del Romancero cidiano que vale la pena considerar por la imagen cultural y estética que intenta transmitir durante su paso por el siglo XVII.

Un principio fundamental de la hipótesis de trabajo para este caso es que los servicios brindados por las herramientas ecdóticas no se pueden ejercer con fines reconstructivos. Estas limitaciones derivan, claro, de la naturaleza particular que el objeto de estudio impone al método: con piezas procedentes tanto del Romancero viejo, como de los Romanceros erudito y nuevo, los textos tienen en muchas ocasiones un tratamiento tradicional en el que las dificultades de la obra culta se van puliendo hasta el grado de no poder pensar en que haya existido

12 Como demuestra Arthur Lee-Francis Askins en "Las primeras ediciones del Romancero de Escobar", en Juan de Escobar, Historia y Romancero del Cid (Lisboa, 1605), ed., est. bibliográfico e índices de A. Rodríguez-Moñino, introd. de A. Lee-Francis Askins, Castalia, Madrid, 1973, pp. 9-34.

13 Françoise Cazal, "L'ideologie du compilateur de "Romances»: remodelage du personage du Cid dans le Romancero e historia del Cid de Juan de Escobar (1605)", en L'ideologie dans le texte (textes hispaniques). Actes du II'rme Colloque du Séminaire d'Etudes Littéraires de l'Université de Toulouse-Le Mirait (Toulouse, février. 1978), Université de Toulouse-Le Mirail, Toulouse, 1978, pp. 197-209. 
una "mejor versión" del romance a los ojos de sus transmisores (aunque sí a los ojos del crítico). Como apunta Samuel G. Armistead, refiriéndose al dinamismo textual del Romancero nuevo, "...muchos romances nuevos enteramente parecen dar fe de una incipiente tradicionalidad, que, si tales poemas llegaran a pervivir, se hubiera convertido en una tradicionalidad tan auténtica y tan cabal como la de cualquier romance viejo"14.

En estas circunstancias de variación textual, a lo más que podemos aspirar es, como apunta Giuseppe di Stefano, quien mejor y con más provecho ha reflexionado sobre la edición crítica del Romancero viejo, "a riprodurre in modo organico ed economico la pienezza della costellazione testuale attestata" 15 . Bajo esta luz, el servicio de un stemma se reduce a "ofrecer una visualización condensada de las posibles relaciones entre los testimonios escritos conocidos del romance, con un mínimo de hipótesis sobre intermediarios perdidos pero detectables con suficiente evidencia" 16 . Esta hipótesis de trabajo, formulada sólo luego de un conocimiento preciso de la tradición del texto, puede incluso influenciar en la constitución del stemma. Así, mientras en los stemmata convencionales cada sigla griega o romana según remite a un testimonio supuesto o a uno real tiene un valor textual asignado, "en nuestro campo mucho más que en otros es símbolo de un estadio textual, de un momento de la tradición que puede entrar en:juego con otros en primera persona o por vía indirecta" 17 .

El conocimiento de la tradición en la fase de la recensio permite determinar el valor de cada lección como representante de estados de variación determinados. La hipótesis de trabajo en la constitutio textus debe, por lo tanto, ser consecuente con esta evidencia. Así, los errores en la edición crítica de romances no pueden considerarse sencillamente como tales; en principio, siguiendo a Giuseppe di Stefano, habría que considerar

${ }^{14}$ Prólogo, en Cancionero de poesías varias, ms. 1587 de la Biblioteca Nacional de Madrid, eds. J. J. Labrador Herraiz y R. A. DiFranco, Visor, Madrid, 1994, p. xv.

15 "II Romance del conde Alarcos. Edizione "critica»", en Symbolae pisanae. Studi in onore di Guido Mancini, a cura di B. Periñán e F. Guazzelli, Giardini, Pisa, 1989, t. 1, p. 188.

16 GiusepPe di Stefano, "El Romance de don Tristán. Edición «crítica» y comentarios", en Studia in honorem prof. M. de Riquer, Quaderns Crema, Barcelona, 1988, t. 3, p. 274.

17 Ibid., p. 278. 
que "es error exclusivamente la falta material de pluma o de imprenta, que se corrige dejando constancia de tales gazapos en una lista final"18. Las diferencias entre lecciones sólo pueden, de momento, considerarse como variantes adiáforas que comparten la misma escala de valores sin que haya que preferir las lecciones de un testimonio a las de otro. Nada más que variantes relacionales -hay que recordar que es solamente a partir de variantes (errores) separativas y conjuntivas que podemos ordenar las ramas en un stemma- y no el binarismo de lección correcta/lección corrompida y texto crítico definitivo/aparato de lecciones rechazadas, inútil cuando se trata de textos en los que las versiones reorganizan su textualidad con el propósito de ofrecer siempre un sentido posible para sus distintos transmisores $(i d$.$) . Así, por ejemplo, en el caso de los cuatro prime-$ ros versos del romance:

\section{Cuidando Diego Laínez en la mengua de su casa, fidalga, rica y antigua, antes de Íñigo Abarca...}

Sabemos que no hay ninguna razón para señalar como correcta o incorrecta alguna de las varias lecciones que ofrecen los otros testimonios, siempre que ninguna de ellas afecta determinantemente el sentido o la res metrica. Esto es, al menos, lo que demuestra el abanico de posibilidades que se despliega ante el editor y su hipótesis de trabajo, una vez configurado el aparato crítico:

$$
\begin{aligned}
& \text { antes de Nuño y Abarca } F^{9} \\
& \text { antes de Yñigo, y Abarca } C^{5} \\
& \text { antes de Íñigo Abarca } C^{12} \\
& \text { antes de Iñigo de Abarca } m p \\
& \text { antes de Ynigo y Abarca } P G \\
& \text { antes de Yñigio Abarca } M
\end{aligned}
$$

18 Gilseppe d Stefano, "Edición «crítica» del Romancero antiguo: algunas consideraciones", en Actas del Congreso Romancero-Cancionero UCLA (1984), ed. E. Rodríguez Cepeda, José Porrúa Turanzas, Madrid, 1990, t. 1, pp. $40-41$. 
En el caso de los nombres, el polimorfismo gráfico está bien documentado para el período. Por lo que toca a la irregularidad en la marcación de sílaba tónica (según la prosodia del verso), veremos que cada testimonio puede leerse de acuerdo con un patrón diferenciado, pero siempre correcto, según las sílabas añadidas o suprimidas al texto y la colocación de las sinalefas o los hiatos.

$$
\begin{aligned}
& \text { án-tes-de-Nú-ño-yA-bár-ca } F 9 \\
& \text { án-tes-deY-ñí-go-yA-bár-ca } C^{5} \\
& \text { án-tes-de-İ-ñi-goA-bár-ca } C^{12} \\
& \text { án-tes-del-ñi-go-deA-bár-ca } m p \\
& \text { án-tes-deY-ní-go-yA-bár-ca } P G \\
& \text { án-tes-deY-ñí-gio-A-bár-ca } M
\end{aligned}
$$

Por el lado de los referentes históricos es bien poco lo que se puede decir del personaje: se alude con este nombre al otro juez de Castilla, pareja de Laín Calvo, Nuño Rasura, parte importante del pasado mítico atribuido al Cid, pero no hay rastros en la historiografía del período para explicar o certificar la equivalencia entre Nuño Rasura y este Íñigo Abarca. El nombre a finales del siglo XVI parece tener sólo un valor connotativo que denota antigüedad, con pocos rasgos referenciales (de ahí posiblemente su notable variación).

Esta consideración sobre los errores no significa, por supuesto, que falten, comparativamente, mejores y peores lecciones. De forma obvia, algunas versiones del romance resultan superiores desde la perspectiva de la comprensión del texto, pero esto no significa automáticamente que las versiones menos buenas carecían de sentido para sus lectores. En general, una lección puede parecer mejor o peor, pero suele tener un sentido al interior del texto, por un sistema de compensación. Cuando Diego Laínez reúne sus fuerzas y aprieta las manos a sus hijos, en los testimonios de la familia $F 9$, es el "honor" inmaterial quien presta vigor al viejo, a "la fría sangre y venas, / neruios y arterias eladas", componentes físicos deteriorados:

Y prestando el honor fuerças a pesar del tiempo y canas a la fria sangre y venas, 
neruios y arterias eladas.

Les apreto de manera que dixeron, señor basta, que intentas o que pretendes dexanos ya que nos matas $(F 91, \mathrm{ff} . \mathrm{M} 2 \mathrm{r}-\mathrm{M} 2 \mathrm{v})$.

Aunque para un lector avezado resulta más lógica y gramatical esta lección conservada en la familia $F 9$, hay que señalar que para los transmisores contemporáneos presentaba serias anomalías. Si revisamos el entramado de usos verbales en los primeros cuarenta versos de la composición, comprobaremos que la mayor parte de las remisiones anafóricas verbales apuntan al núcleo elíptico "Diego Laínez", tanto en los verbos conjugados como en los gerundios ${ }^{19}$. Contra esta tendencia absoluta en la construcción, "Y prestando el honor fuerças..." es una oración de gerundio adjunto externo que tiene un sujeto propio explícito ("el honor") distinto del sujeto de la oración principal que ha dominado hasta ahora ("Diego Laínez") ${ }^{20}$. Resulta natural que ante la presencia mayoritaria de gerundios adjuntos internos referidos en su totalidad al núcleo elíptico "Diego Laínez", se tendiese en las versiones posteriores hacia la uniformidad, homogeneizando el único caso de un gerundio adjunto externo con un sujeto propio como "Y prestando el honor fuerças".

Así, Juan de Escobar ensaya una construcción en la que se respeta el paradigma de los gerundios adjuntos internos, construido sobre el modelo del incipit "Cuidando Diego Laínez", dando como resultado una oración en la que se elimina el sujeto propio ("el honor") al transformarlo en objeto dativo ("al honor"), con lo que se restituye el valor de "Diego Laínez" como núcleo elíptico ("Mas [Diego Laínez] prestando al honor fuerças"). Incluso contra el sentido, pues mal puede entenderse

19 "Diego Laínez" funciona como núcleo elíptico en "puede" (vv. 8 y 9), "niega" (v. 14), "mandó" (v. 21), "apretó" (v. 33) y "llegó" (v. 37); esta densidad semántica del núcleo elíptico se confirma en los gerundios adjuntos internos que refieren a "Diego Laínez" en "viendo [Diego Laínez]..." (v. 5); "temiendo [Diego Laínez]" (v. 15); "estando pues combatiendo [Diego Laínez]..." (v. 17); anáforas construidas sobre el modelo del incipit: "Cuidando Diego Lainez..." (v. 1).

20 Sobre la distinción entre gerundio adjunto interno y externo, véase Alicia Yllera, "Los gerundios adjuntos externos" y "Gerundios adjuntos internos", en Gramática descriptiva de la lengua española, dirs. I. Bosque y V. Demonte, RAE-Espasa, Madrid, 1999, 53.4 y 53.5. 
cómo presta el anciano "fuerças" a este "honor" maltrecho y a estas "sangre y venas", "niervos y arterias eladas", cuando en los vv. 5-8 se ha señalado que "le fallecen / fuerças para la vengança" y que "por sus luegos días / por sí no puede tomalla":

Mas prestando al honor fmerças,

al pesar del tiempo y canas,

a la fría sangre y venas,

niervos y arterias eladas,

les apretó de manera...

La rama $\beta$ confirma el triunfo de esta reinterpretación de la frase con una solución gramaticalmente idéntica (que bien pudo servir de guía en la decisión de Escobar): "Y poniendo [Diego Laínez] al honor fuerça". El escaso éxito de la lección de $F 9$, que parecería indudablemente más correcta desde un punto de vista artístico y gramatical, se ciñe a las reglas de la unidad sintáctica que recorre los primeros cuarenta versos de la composición, ijustificada por el lugar privilegiado del antecedente "Diego Laínez" como incipit del romance y por las remisiones anafóricas de prácticamente todos los verbos en esta sección (núcleos verbales y gerundios) al núcleo elíptico. En casos como los anteriores, una revisión de la constelación textual en torno a una lección permite describir el proceso del paso de una lectio difficilior a una lectio facilior, donde la lectio facilior exhibe una dificultad hermenéutica que se va puliendo con lecciones sucesivas, en las que se intenta configurar una lección más adecuada a las posibilidades de los receptores.

Siguiendo los pasos del método y con un espíritu semejante al que obliga a considerar los "errores" desde otra perspectiva, la eliminatio codicum descriptorum es un principio que no podemos seguir bajo ninguna circunstancia en la fase de la constitutio textus, para mantener cierta coherencia con la hipótesis de trabajo. Aun en el caso de los codices descripti, como también ha señalado ya Giuseppe di Stefano, "cualquier testimonio, sea cual sea su colocación en el stemma, tiene la misma validez de los demás" ${ }^{21}$. De hecho, si intentásemos aplicar la eliminatio codicum descriptorum nos encontraríamos en serios problemas, pues no son pocos los casos en que los testimonios de una misma familia y una misma rama muestran contaminaciones,

21 “Edición «crítica» del Romancero antiguo...", p. 37. 
como sucede en nuestro ejemplo con los casos en que $G^{3}$ reproduce lecciones del Romancero general de 1600 sin pasar por $G^{2}$ (10 gustar $G^{1} G^{3}$ gastar $G^{2}$ o $56-57$ fiereza $G^{1} G^{3}$ firmeza $\left.G^{2}\right)$ o con el elenco de soluciones procedentes de $\alpha$ y $\beta$ en el manuscrito $m p$. Muchas veces, cuando se presenta cierta estabilidad entre testimonios relacionados por segundas y terceras ediciones en una misma colección de romances, resulta posible referirse a familias (representadas en el stemma por nexos horizontales). Queda así reflejada tanto en los preliminares de la recensio como en el aparato crítico final la mediación de la imprenta como un principio de relativa estabilidad en la transmisión textual, frente a la naturaleza contaminadora de los manuscritos (muchas veces, como sucede con $m p$, basados en los recuerdos de versiones diferentes) o a la originalidad de los pliegos sueltos. En el aparato crítico, esta relativa estabilidad entre los miembros de una familia editorial queda expresada por fórmulas de colación más económicas, en las que una sigla asignada por familia permite dar cuenta de lecciones coincidentes de todos los miembros (donde $G$ da cuenta de las lecciones coincidentes de $G^{1}, G^{2}$ y $G^{3}$ ).

Esta evaluación previa tiene como propósito, por supuesto, preparar un marco de principios fehacientes que permitan orientar nuestras decisiones posteriores y calificarlas de criticas. En el caso de la dispositio textus, la hipótesis de presentación orgánica y económica de la tradición del Romancero e historia del Cid, considerando cada romance en su transmisión individual, pero sin perder de vista que el anclaje de cada texto es un grupo textual acotado por la copilación de Juan de Escobar y su familia impresa, sugiere una presentación gráfica del testimonio de referencia que tenga en cuenta las características del paso del grupo por la imprenta. La posibilidad de concentrarse en el estudio de una sola familia impresa -o en el de un solo testimonio-permite mayor rigor y promete conclusiones más ricas en la toma de decisiones respecto a su constitución gráfica.

En este caso particular, después de un estudio cuidadoso del comportamiento de $C^{12}$, he seguido con ciertas libertades la propuesta de transcripción de Barroso Castro y Sánchez de Bustos $^{22}$; así, el lector podrá comprobar que casi en todos los

22 José Barroso Castro y Joaquín Sánchez de Bustos, "Propuesta de transcripción para textos del xv y Siglos de Oro", en Estado actual de los estudios sobre el Siglo de Oro. Actas del II Congreso Internacional de Hispanistas del Siglo 
casos se ha privilegiado la conservación de alógrafos denotativos o connotativos -representación gráfica objetiva de una realidad fonética sin valor atribuido de relevancia cultural o estilística y representación gráfica de una realidad fonética con valor atribuido de relevancia cultural o estilística, respectivamente ${ }^{23}$ - por encima de la regularización acrítica.

Aunque no es lugar aquí para una exposición detallada, adelantaré que la grafemática del impreso de 1612 de Alcalá suele ser muy correcta y uniforme con ciertos modelos grafemáticos (corrección que se contradice con la clara decadencia material de los tipos empleados) ${ }^{24}$, por lo que probablemente en varios romances podría mantenerse acaso sin ninguna enmienda que no sean las erratas. Recuérdese que la hipótesis de trabajo no es reconstructiva. En el caso de las sibilantes, por ejemplo, el texto no ofrece testimonio de dobletes y presenta, por el contrario, ejemplos muy interesantes de fidelidad entre grafías y lexemas ${ }^{25}$ (esto, por supuesto, sin suponer que responde a los usos actuales: se trata de una coherencia interna dentro de los usos particulares del taller de Juan Gracián). Contradice esta regularidad la presencia de dobletes del tipo hijo(s)/fijo(s), hidalgo(s)/fidalgo(s), no/non, ni/nin, etc., y obligan a considerar la regularización de estos loci critici o su simple modernización. Un estudio cuidadoso de todos los casos demuestra, frente a este tipo de decisiones mecánicas, que no es posible ni la regularización gráfica ni la simple modernización, pues cualquiera de estas acciones acríticamente tomadas estaría alterando la prosodia de los testimonios. En general, los dobletes deben conservarse, pues de restablecer, por ejemplo, la f- etimológica con efecto arcaizante en "y quatro hijos que tenía" (XXXI, 28), terminaríamos con un verso hipermétrico. Con relación a los dobletes no/non y ni/nin, se tendría que

de Oro, eds. M. García Martín, I. Arellano, J. Blasco y M. Vitse, Universidad, Salamanca, 1993, t. 1, pp. 161-178.

23 Véase la definición de ambos en ibid., pp. 161-165.

${ }^{24}$ Recordemos que la imprenta de Juan Gracián empezó sus labores hacia 1568 y continuó sostenida, luego de su muerte en 1587 , por su viuda, hasta 1624, lo que explica el desgaste de los tipos. Véase María Marsá, La imprenta en los Siglos de Oro (1520-1700), Laberinto, Madrid, 2001, p. 106.

${ }_{25}$ Así, escribe fuerças (I, 6 y 29), vengança (I, 6; XVIII, 59), alçar. (1, 11), braço $(s)(\mathrm{I}, 57$; XVII, 27; XVIII, 51), fallecen $(1,5)$, nacido $(\mathrm{I}, 28)$, naciere (XVII, 83), bracero (XVIII, 52), Cid (XVIII, 4 y 46), etc., pero decirles (1, 22), dize (1, 44; XVIII, 8 y 45), dezisme (XVII, 17), dezis (XVII, 22, 57 y 65), hiziera (1, 47), faziendo (1,51), fazañas $(1,64)$, fazer (XVII, 5), gozo $(1,53)$, razon (XVII, 32), razones (XVII, 69), etc. 
operar del mismo modo en tanto alternan frecuentemente por razones de arcaísmo o de prosodia. Se ha conservado esta vacilación, pues en muchos casos ilustra el deseo de obtener una forma gráfica arcaizante y la imposibilidad de adecuar este artificio a la prosodia del verso. El primer romance describe bien esta situación:

no puede dormir de noche,

10 nin gustar de las viandas, ni alçar del suelo los ojos, ni osar salir de su casa, nin fablar con sus amigos, antes les niega la fabla

15 temiendo que les ofenda el aliento de su infamia.

Una regularización de estos dobletes provocaría, si uniformamos en "nin", una hipermetría en los vv. 11-12; si uniformamos en "ni", violentaríamos la intención arcaizante de Escobar (v. 10y 13), quien sigue en general las convenciones del Romancero en su tiempo.

Como puede verse hasta aquí, sólo se ha regularizado la vacilación entre la $\mathrm{u} / \mathrm{v}$, neutralizada ya muy tempranamente por los gramáticos de la época ${ }^{26}$, restableciendo el valor vocálico o consonántico. En cuanto a la vacilación y/i, también se ha optado, bajo el mismo criterio, por restablecer el valor vocálico de i y el consonántico de y -siguiendo, claro, la convención moderna-, que mantiene y con valor vocálico en la conjunción y en los casos de rey, ley, contray, hoy, ete. ${ }^{27}$.

Con el propósito de guiar la lectura en ciertos octosílabos que pueden resultar conflictivos para un lector distraido, acentúo en todos los casos. Asi, debe leerse por razones prosódicas "Cuidando Diego Laínez" (La-í-nez) y no "Cuidando Diego Lainez" o "antes de Inigo Abarca" (de-i-ñi-go) y no "de Iñigo Abarca". La acentuación ayuda sin duda a mantener la regularidad métrica en casos donde una sinalefa mal colocada puede volver un verso hipométrico.

Sobre la interpunción, la notable variación de la puntración entre los testimonios permite vislumbrar un cuadro am-

26 Véase lo que al respecto escriben Barroso Castro y Sanchez de BusTos, art. cit., pp. 172-174.

27 Ibid., pp. $175-176$. 
plio de convenciones editoriales en el que tienen cabida decisiones muy distintas. Así, la puntuación en $\mathrm{F}^{91}$ y $\mathrm{C}^{5}$ sigue las normas de la imprenta de la época: como en los textos en prosa o el teatro en verso ${ }^{28}$, conserva [,] en las enumeraciones y antes de la conjunción [y] (en algunos casos, como en el de w. 3-4 en $C^{5}$, incluso contra la prosodia natural del verso); como efecto colateral del estrofismo del Romancero nuevo, el [.] servirá mayoritariamente para señalar el fin de la cuarteta con independencia muchas veces del sentido o sintaxis de la frase. En el caso de $C^{12}$, este papel muchas veces se confía indistintamente a la [,] o a los [:], lo que demuestra la multifuncionalidad de los signos de puntuación y una voluntad hermenéutica distinta:

$F 9 !$

Cvydando Diego Layncz en la mengua de su casa fidalga, rica, y antigua, antes de Nuño y Abarca. Y viendo que le fallecen fuerças para la vengança, porque por sus luengos años por si no puede tomalla. Y que el de Orgaz se passea seguro y libre en la plaça, sin que nadie se lo impida Loçano en nombre y en gala. Non puede dormir de noche nin gustar de las viandas, ni alçar del suelo los ojos ni osa salir de su casa.

Nin fablar con sus amigos antes les niega la fabla, temiendo no les ofenda el aliento de su infamia.

$\begin{array}{ll}C^{5} & C^{i 2} \\ \begin{array}{l}\text { CVDANDO Diego Laynez } \\ \text { en la mengua de su casa, }\end{array} & \text { en la mengua de su casa } \\ \text { fidalga, rica, y antigua, } & \text { fidalga rica y antigua } \\ \text { antes de Yñigo, y Abarca. } & \text { antes de Yñigo Abarca: } \\ \text { Y viendo que le fallecen } & \text { y viendo que le fallecen } \\ \text { fuerças para la vengança, } & \text { fuerças para la vengança, } \\ \text { porque por sus luengos días } & \text { porque por sus luengos días } \\ \text { por si non puede tomalla, } & \text { por si no puede tomalla, } \\ \text { non puede dormir de noche, } & \text { no puede darmir de noche, } \\ \text { nin gustar de las viandas, } & \text { nin gustar de las viandas, } \\ \text { ni alçar del suelo los ojos, } & \text { ni alçar del suelo los ojos, } \\ \text { ni osa salir de su casa, } & \text { ni osar salir de su casa, } \\ \text { nin fablar con sus amigos } & \text { nin fablar con sus amigos, } \\ \text { antes les niega la fabla, } & \text { antes les niega lo fabla } \\ \text { temiendo que les offenda } & \text { temiendo que les ofenda } \\ \text { el aliento de su infamia. } & \text { el aliento de su infamia: }\end{array}$

28 Véase, por ejemplo, Lavrette Godnas, "Entre ecđótica y pragmática: la puntuación en los impresos dramáticos españoles y novohispanos", en Actas del XI Congreso de la Asociación. Internacional de Teatro Español y Novohispano de los Siglos de Oro, en prensa. 
Si revisamos comparativamente el uso de la puntuación, podremos observar que algunos testimonios tienen comportamientos particulares: mientras en la familia $F 9$ y en $C^{5}$ domina la marcación de las cuartetas, en $C^{12}$ Juan de Escobar (o un cajista del taller de Juan Gracián) parece más preocupado por subrayar la continuidad sintáctica del discurso (marcada, como he apuntado, por la elipsis del núcleo y constantes remisiones anafóricas). Resulta difícil aventurar algunajustificación, pero es probable que el conocimiento de varias fuentes distintas del Romancero, durante el proceso de búsqueda y selección de los textos, haya contribuido a romper el esquema estrófico.

La comparación, en todo caso, apunta a un uso y valores de la puntuación ajenos al uso actual o sustituibles (como en el caso de las marcas de terminación de estrofa), por lo que pueden tomarse algunas decisiones al respecto que convivan con el conservadurismo gráfico. Así: a) dentro del cuadro de convenciones editoriales que fijó el canon del Romancero nuevo, por razones musicales y luego, probablemente hermenéuticas, la unidad sintáctica para indicar períodos (con equivalencias sintácticas: oración, predicado, circunstanciales, etc.) suele coincidir con unidades equivalentes a cuatro versos o sus múltiplos, por lo que se optó por apuntar esta característica con sangrías al principio de cada grupo (las omisiones más importantes, por ejemplo, suelen coincidir con esta unidad, tanto en el caso de autocensura, como en el de probables saltos ex homoioteleuton); b) la unidad mínima suele ser gramatical -vocativos, por ejemplo-; en estos casos, he preferido no romper el ritmo natural del verso con señalamientos gráfico/gramaticales que una lectura medianamente atenta puede resolver. Hago eco de las palabras de Di Stefano: "he preferido confiar la pausa al ritmo normal del verso más que a la presencia del signo gráfico"29. En los casos en que una puntuación suave ofrezca alguna ambigüedad, sin embargo, deberá reforzarse alguno de los sentidos posibles o comentarse en el aparato crítico, como sucede en el v. 45:

-Soltedes, padre en malhora, soltedes, en hora mala, que a no ser padre no hiziera satisfación de palabras, 
La ausencia de interpunción en el primer verso daría pie a dos lecturas distintas. Por un lado, "Soltedes, padre, en malhora", donde "padre" tiene una función de vocativo y "en malhora" es un circunstancial que califica al verbo; por el otro, "Soltedes, padre en malhora," (la puntuación escogida para el texto crítico), donde la calificación negativa se atribuye directamente a "padre", en consonancia con la observación final "a no ser padre no hiziera / satisfación de palabras", sino satisfacción de hechos). Dejar de puntuar en este caso hubiese significado dejar el peso de la interpretación en manos del lector.

En cuanto a signos de admiración, interrogación, guiones largos para los parlamentos, etc., se restituyen según la norma actual (ante la falta de una normatividad al respecto en el impreso de Alcalá y, en general, en los impresos de la época); se ha evitado el punto y coma [;] y en todos los casos se han utilizado coma [,] y punto [.] únicamente para no sobrecargar el texto crítico.

Por lo que toca al aparato de variantes, el aspecto económico de nuestra representación sugeriría mantener normas paleográficas para el registro de las variantes en otros testimonios, pues resultaría arduo para el lector y para el editor formular y aplicar normas de coherencia sobre la presentación gráfica de todos los testimonios, teniendo fuentes de procedencia tan heterogénea (desde manuscritos, hasta pliegos sueltos y romanceros). Se ha procedido de este modo y se ha recurrido a un aparato positivo, con el propósito de facilitar el viaje del lector por la intrincada selva que puede representar un aparato de variantes donde falta la verticalidad de la hipótesis reconstructiva.

\section{¿OTRAS HIPÓTESIS DE TRABAJO?}

Hasta aquí, mi preocupación ha sido bosquejar la hipótesis de trabajo más adecuada para una edición crítica del corpus completo de los romances reunidos hacia 1605 por Juan de Escobar y articulados en torno a una progresión narrativa de los materiales copilados. La pregunta que queda abierta, por supuesto, es si hay otras posibles hipótesis de trabajo que valga la pena explotar. La respuesta es afirmativa. Una hipótesis de trabajo no agota el campo posible y es bajo este principio que cada nueva edición crítica de un mismo texto puede considerarse distinta siempre que apunte a resolver una nueva hipótesis de trabajo. 
Respecto a este romance en particular, mi amigo Antonio Carreira veía muchas posibilidades de mejoramiento estético y de sentido en la elección de un testimonio más temprano de la rama $\alpha$, advirtiendo la incorporación temprana de deturpaciones viciosas, desde el pliego suelto de 1595, que entorpecian la andadura de un romance nuevo anónimo, pero procedente de una pluma con ciertos vuelos del ingenio. Esta hipótesis, válida si los romances del corpus seleccionado por Escobar se editaran por separado, no deja de ser atractiva. De seguir esta línea, el stemma codicum serviría para explicar el camino que una composición culta seguiría al incorporarse a un proceso de transmisión popular dentro de un Romancero tan heterogéneo como el que confecciona Juan de Escobar a principios del siglo Xvi.

En este caso, el análisis de las variantes permitiría visualizar un estado de composición "más correcto" sólo en las ramas más al tas del stemmay, consecuentemente, las más cercanas a un original. Siguiendo esta lógica, los testimonios más valiosos para la conformación de un texto crítico serían los correspondientes a la familia $F 9(1597$ y 1600$)$ y a $P(1595)$, que presentan en tre sí las siguientes lecciones variantes:

2 en la mengua $F 9$ por las menguas $P$

4 Nuño y Abarca $F 9$ Ynigo y Abarca $P$

7 porque $F 9$ y que $P$

8-9 seguro y libre $F 9$ libre y essento $P$

9 Non puede $F 9$ no puede $P$

10 nin $F 9$ ni $P$

12 ni osar $F 9^{2}$ ni osa $F 9^{1} P \mid$ de su casa $F 9$ de la sala $P$

13 nin fablar $F 9$ Nin fabla $P$

19 cierta esperiencia $F 9$ vna esperiencia $P$

23 les fue apretando vno a vno $F 9$ les apretara vno a vno $P$

25 en ellas $F 9$ en ello $P$

27 que este $F 9$ que aquel $P$

28 no era nacido $F 9$ no auia nacido $P$

$29 \mathrm{Y}$ prestando el honor fuerças $F 9$ Y puniendo al honor fuerça $P$

43 con tanta yra $F 9$ con tal semblante $P$ 
44-45 Sacò F9 Sacando $P$

$44-45$ y la diestra mano saca $F 9$ la mano diestra sacara $P$

$44-45$ y buelto a su padre dize $F 9$ y al viejo padre le dize $P$

$44-45$ a faz $F 9$ que azaz $P$

46 solteys muy en hora mala $F 9$ soltes padre en hora mala $P$

47 serlo $F 9$ sello $P$

48 con palabras $F 9$ con palabra $P$

49 con la mano misma $F 9$ con mis propias manos $P$

51 mi dedo $F 9$ mi braço $P$

53 Llorando de gozo el viejo $F 9$ El padre llora de gozo $P$

56-57 Essa fiereza assegura / con abonada fiança, / el agrauio a mi fecho / en tu esfuerço y hechos de armas om. $F 9$

57 Essos fieros $F 9$ Esos brios $P$

58 teneldos $F 9$ muestralos $P$

60 si en vos $F 9$ sin ti $P$

62 la espada $F 9$ el espada $P$

63 dio al Conde la muerte $F 9$ dio la muerte al Conde $P$

64 hazañas $F 9$ fazañas $P$

En varios casos, $F 9$ transmite lecciones superiores procedentes probablemente de un testimonio anterior a $P$, que resulta consecuentemente más descuidado en su factura. Así, lecciones como "Y prestando el honor fuerças" ( $F 9$, v. 29) es mejor porque rompe con la monótona secuencia de gerundios adjuntos internos, mientras que $P$. sucumbe a una lectio faciliory transforma el rasgo de originalidad en "Y puniendo al honor fuerça", un gerundio adjunto interno. En los vv. 49-52, la amenaza del Cid en $F 9$ resulta violenta e intimidante, pero verosímil ("antes con la mano misma / vos sacara las entrañas, / faziendo lugar mi dedo / en vez de puñal o daga"); en $P$, se cargan las tintas para impresionar más al lector: ahora serán dos las manos que sirvan para arrancar las entrañas ("con mis propias manos") y en vez del dedo de $F 9$, será todo el brazo el que sustituya al "puñal o daga”. Teniendo en cuenta las dimensiones del término de comparación ("puñal o daga"), parece más probable que en el original se concibiera realizar esta tarea con un dedo y que ahora se 
hiperbolice en $P$. En $F 9$, se apunta en la lección que el honor está perdido "si en vos no se cobra y halla"; en $P$ claramente el sitio se ha deturpado por "sin ti no se cobra y halla" (v. 60). En el caso de la variantes "Essos fieros" en $F 9$ y "Esos brios" en $P$, podría parecer sencillamente que "brios" es una lectio facilior de "fieros", sustantivo con un significado en apariencia poco claro para sus transmisores contemporáneos, a juzgar por el rechazo en los testimonios posteriores (dando, por ejemplo, "essos braços" en $C^{5}$ ). La variante, sin embargo, involucra más que una mera incomprensión del término. Entre los vv. 56-57, $P$. conserva una cuarteta que, por el contrario, falta en $F 9$. Con precaución, me he referido a su falta y no directamente a su "omisión" en $F 9$, pues antes habría que determinar si se trata de una cuarteta innovadora (añadida probablemente en $P$ ) o si estamos sencillamente delante de una omisión, también temprana, al menos desde 1597 , en $F 91$, con lo que podría empezar a perfilarse el comportamiento de cada una de las familias. Considero que hay evidencia suficiente para pensar en una adición de $P$. (y luego de toda la rama $\beta$ ), ejecutada probablemente para llenar el espacio de la columna del $\mathrm{f}$. A3r en el pliego suelto de 1595, donde la versión original del parlamento de Diego Laínez pudo amplificarse de una a dos cuartetas para colmar el espacio y terminar el f. A3r con este romance. Si se compara $F 9^{1}$ con $P$, se pueden advertir huellas del proceso de amplificación (vv. 53-60):

F9I.

Llorando de gozo el viejo, dize, fijo de mi alma tu enojo me desenoja, $y$ tu indignacion me agrada.[f.134v]

Essos fieros mi Rodrigo teneldos en la vengança de mi honor que esta perdido si en vos no se cobra y halla.

Contole su agrauio y diole su bendicion y la espada con que dio al Códe la muerte, y principio a sus hazañas. [f. 135r]

\section{$P$}

El padre llora de gozo, dize fijo de mi alma, tu enojo me desenoja, y tu indignación me agrada. Essa fiereza assegura
con abonada fiança
el agrauio a mi fecho
en tu esfuerco y hechos de

Essos brios mi Rodrigo muestralos en la vengança de mi honor que esta perdido, sin ti no se cobra y halla.

Contole su agrauio, y diole su bendicion, y el espada con que dio la muerte al Conde y principio a sus fazañas.

Fin. [f. A3r] 
Las dos cuartetas en $P$ muestran algunos rasgos que apuntan a una amplificatio apresurada. Los versos con que inician las cuartetas en $P$ presentan una clara diseminación del v. 57, convirtiendo "Essos fieros mi Rodrigo..." en "Essa fiereza asegura..." y "Essos brios mi Rodrigo..." (sin posibilidad de mantener al principio del verso "Essos fieros...", pues ya antes se había apuntado "fiereza" y el transmisor advierte una falsa relación de sinonimia por la semejanza formal). En el caso de $F 9$, el diálogo del padre tiene un solo tema central: su contento por el enojo del hijo (vv. 55-56) y la demanda de que esos "fieros" que ahora ve (definidos por el Dicc. Aut. como "bravatas y baladronadas con que alguno intenta aterrar a otro") estén también presentes en la venganza de su honor. En $P$, entre el contento por el enojo del hijo y la demanda de que ese enojo sirva para rescatar su honor se introduce un tema nuevo: la garantía que ve el padre en la "fiereza" para refrendar "el agravio a mí fecho", aludiendo a un "esfuerço" y a unos "hechos de armas" cuyos antecedentes faltan en el romance, pues lo que en realidad ha probado el padre son los "fieros" de sus hijos y no sus "hechos de armas" (sin perder de vista que en la última cuarteta se apunta justamente que, con la muerte del conde Lozano, Rodrigo Díaz da "principio a sus fazañas").

Sólo en un caso me parece que puede resultar preferible la lección de la familia F9. Cuando el Cid responde al padre, se señala en el romance la atención de éste hacia la respuesta del hijo, apuntando en $F 9$ que "a faz mirandole estaua" (que le miraba el rostro, como puntualizará luego $G^{l}$ con la lección "la faz") y en $P$ que "azaz mirando le estaua". En el primer caso, se indicaría simplemente que el padre escrutaba el rostro del Cid, mientras que en el segundo caso, preferible por el contexto en el que se hace dicho señalamiento, se apuntaría a la sobrada atención con que el padre mira (como se infiere del sentido de "assaz" en el Dicc. Aut:: "en abundancia, sobrada y abundantemente"). Obviamente, $F 9$ ha cometido una lectio facilior al confundir una s larga con una fo al topar con dos ss largas, una de ellas quizá mal entintada, e interpretar "a faz".

$\mathrm{El}$ análisis de estas lecciones, me parece, ofrece razones suficientes para preferir el testimonio de $F 9$ como base para un texto crítico que se aproxime a una versión más correcta del romance. Los límites de esta hipótesis son, sin embargo, claros. Dicha hipótesis de trabajo sólo serviría para la edición de un texto, el de este romance, y no para todo el Romancero e historia 
del Cid (pues lo que se edita en este caso es una visión de conjunto del proyecto de Juan de Escobar, y no sencillamente un romance). Editar todo el Romancero e historia a partir de las mejores lecciones conservadas, especialmente en el caso de los romances nuevos, terminaría por ofrecer una visión falseada del nuevo producto cultural e ideológico que ofrece Juan de Escobar al articular los materiales copilados en una historia orgánica y coherente, recreando un Romancero que no existió jamás para los lectores del siglo XvII.

Una hipótesis de trabajo de esta naturaleza sólo sirve para una parte del corpus escobariano, notablemente aquella vinculada al Romancero nuevo y también probablemente aquella relacionada con el Romancero erudito, pero no serviría para dar cuenta de una tarea emprendida con un fin: poner en manos del gran público una historia llamativa como ésta, que si para los lectores de principios del siglo xvi había sido suficiente recibirla bajo la forma de la Crónica particular, ahora la demanda se orientaba hacia su presentación poética, una vez esquilmadas las asperezas formales e ideológicas de los Romanceros erudito y nuevo. Presentar las mejores versiones de uno y otro traicionaría este proceso de desbastado que emprendió Juan de Escobar y que, sin evitar por completo una selección crítica de la mejor versión (finalmente, de entre todas las versiones posibles, Juan de Escobar eligió la que mejores lecciones presenta, y no simplemente la más antigua, como hizo el copilador del Romancero general de 1600), garantizó sin embargo la fama de este Romancero e historia del Cid a lo largo y ancho de todo el siglo XVII y más allá, cepilladas sus versiones de varias dificultades formales o ideológicas.

\section{El VALOR DE LA HIPÓTESIS DE TRABAJO}

Como se ha visto hasta aquí, la edición crítica como hipótesis de trabajo es un concepto metodológico importante y valioso como herramienta de control de nuestras decisiones en la etapa de la constitutio textus. Su virtud, más allá de la meraijustificación de las conjeturas de la emendatio ope ingenii, consiste en presentar la edición crítica como un conjunto de decisiones probadas y decisiones conjeturales dentro del marco coherente y organizado de la hipótesis de trabajo. Esto significa, probablemente, que en la edición crítica la intervención del editor va más 
allá de las meras enmiendas conjeturales, pero al mismo tiempo permite explicitar en este ir más allá una toma consciente y responsable de decisiones que pretenden ser orgánicas con el sistema complejo de decisiones final que es la edición crítica. Esto es lo que he intentado mostrar en las presentes páginas.

Alejandro Higashi Universidad Autónoma Metropolitana-Iztapalapa

\section{APÉNDICE}

\section{ROMANCE PRIMERO}

Cuidando Diego Laínez en la mengua de su casa, fidalga, rica y antigua, antes de Íñigo Abarca, $y$ viendo que le fallecen fuerças para la vengança, porque por sus luengos días por sí no puede tomalla, no puede dormir de noche, nin gustar de las viandas, ni alȩar del suelo los ojos, ni osar salir de su casa, nin fablar con sus amigos, antes les niega la fabla temiendo que les ofenda el aliento de su infamia.

Estando pues combatiendo con estas honrosas bascas, para usar de una esperiencia que no le salió contraria mandó llamar a sus hijos y $\sin$ dezirles palabra les fue apretando una a una las hidalgas tiernas palmas, no para mirar en ellas las quirománticas rayas, que este fechizero abuso no era nacido en España.

Mas prestando al honor fuerças, al pesar del tiempo y canas, a la fría sangre y venas, niervos y arterias eladas, 
les apretó de manera que dixeron:-Señor basta. ¿Qué intentas o qué pretendes? ¡Suéltanos ya que nos matas!

Mas quando llegó a Rodrigo casi muerta la esperança del fruto que pretendía, que a do no piensa se halla.

Encarnizados los ojos cual furiosa tigre Ircana, con mucha furia y denuedo, le dize aquestas palabras: Soltedes, padre en malhora, soltedes, en hora mala, que a no ser padre no hiziera satisfación de palabras, antes con la mano mesma vos sacara las entrañas faziendo lugar el dedo en vez de puñal o daga.

Llorando de gozo el viejo dixo: -Fijo de mi alma, tu enojo me desenoja y tu indinación me agrada, estos braços, mi Rodrigo, muéstralos en la demanda de mi honor que está perdido si en ti no se cobra y gana.

Contóle su agravio y diole su bendición y la espada con que dio al Conde la muerte, y principio a sus fazañas.

Texto crítico: $C^{12}$ ff. 5 r-6r.

\section{Testimonios}

$F 9^{1}$ ff. $133 \mathrm{v}-135 \mathrm{r}, F 9^{2}$ ff. $133 \mathrm{v}-135 \mathrm{r}, C^{5}$ ff. $1 \mathrm{r}-2 \mathrm{v}, m p$ ff. $191 \mathrm{r}-191 \mathrm{v}, P$ ff. $\mathrm{A}^{2} \mathrm{r}-$ $\mathrm{A}^{3} \mathrm{r}, G^{1}$ f. $362 \mathrm{r}, G^{2}$ ff. $358 \mathrm{r}-358 \mathrm{v}, G^{3}$ ff. $360 \mathrm{v}-361 \mathrm{r}, M$ ff. [lr-lv].

\section{FAMILIAS}

$$
\begin{aligned}
& \alpha: F 9^{1} F 9^{2} C^{5} C^{12} m p \\
& F 9: F 9^{1} F 9^{2} \\
& C: C^{5} C^{12} \\
& \beta: P G^{1} G^{2} G^{3} M \\
& G: G^{1} G^{2} G^{3}
\end{aligned}
$$




\section{VARIANTES}

2 en la mengua $\alpha$ ] por las menguas $\beta 3$ rica $\alpha P G^{l} G^{3}$ ] noble $G^{2} M 4$ Íñigo Abarca $C^{12}$ ] Yñigo, y Abarca $C^{5}$ Nuño y Abarca $F 9$ Iñigo de Abarca $m p$ Ynigo y Abarca $P G$ Yñigio Abarca $M 5$ le fallecen cett. ] la fallecen $m p 7$ porque $F 9 C$ ] y que cett. $\mid$ días $C]$ años cett. 8 no puede cett.] non puede $C^{5} 8-9$ Y que el de Orgaz se pasea / libre y esento \{seguro y libre $F 9 m p$ \} en la plaça, / sin que nadie \{sin aber quien $m p\}$ se lo impida / lozano en el nombre y gala \{loçano en nombre y en gala $\{$ galas $m p\} F 9 m p P\}$ om. $C 9$ no puede cett. $]$ Non puede $F 9 C^{5}$ 10 nin $\alpha$ ] ni $\beta$ | gustar cett.] gastar $G^{2} 12$ ni osar $\left.F 9^{2} C^{\prime 2}\right]$ no osa $M$ ni osa $F 91 m p C^{5} P G \mid$ de su casa $\alpha$ ] de la sala $\beta 13$ nin fablar $F 9 C$ ] ni fablar $m p M$ Nin fabla $P G 15$ que les ofenda $C m p]$ no les ofenda cett. 16 el aliento cett. $]$ el asiento $M 18$ honrosas bascas cett.] honradas vascas $C^{5} 19$ para usar de una esperiencia $C]$ quiso hazer cierta esperiencia $F 9$ para haçer cierta esperiençia $m p$ quiso hazer vna esperiencia \{ispirencia $M$ experiencia $G\} \beta 21$ a sus hijos $C m p$ ] sus tres fijos $F 9 P G$ sus tres hijos $M 22$ dezirles $C m p$ ] fablalles cett. 23 les fue aprentando una a una $C]$ les fue apretando vno a vno $F 9 \mathrm{mp}$ les apretara vno a vno $P G$ les aprieta vno auno $M 24$ las cett.] sus $m p \mid$ hidalgas $C]$ fidalgas cett. 25 No $m p M]$ Non $F 9 C^{5} P G \mid$ en ellas $\left.\alpha M\right]$ en ello $P$ en ellos $G 27$ que este $\alpha$ ] que aqueste $M$ que aquel $P G 28$ no era nacido $\alpha$ ] no auia nacido $\beta$ 29 Mas prestando al honor fuerças $C]$ Y prestando el honor fuerças $F 9 Y$ poniendo \{puniendo $P\}$ al honor fuerça $\beta$ 29-32 om. mp 30 al pesar $C^{12}$ ] a pesar cett. 32 niervos $\left.C^{12}\right]$ neruios cett. 33 les apretó de manera cett.] Y apretóles de manera $m p 34$ Señor cett.] Señó $m p 36$ Suéltanos $C m p]$ dexanos cett. 40 que a do no piensa $C m p]$ que do no piensan $F 9 P G^{l} G^{2} M$ que do no piensa $G^{3} 41$ $44 \mathrm{om} . \mathrm{mp} 42$ cual furiosa tigre Ircana $C$ ] qual fiera tigre de Yrcania [Hircania $P G\} F 9 P G$ qual Tiger de Hircania $M 43$ con mucha furia $C]$ con tanta yra $F 9$ con tal semblante $\beta 44$ le dize aquestas palabras $C$ ] que atemoriza y espanta celt. 44-45 Sacando \{Sacò $F 9$ hechó $m p$ \} atras el pie izquierdo / la mano diestra sacara \{y la diestra mano saca $F 9 m p\}$ / y al viejo padre le dize \{y buelto a su padre dize $F 9 m p\}$ / que asaz $\left\{\right.$ la faz $G^{1}$ a faz $\left.F 9 G^{2} G^{3}\right\}$ mirando le estaua $\{q u e$ en esta guisa miraba $m p\}$ om. $C 45$ padre en malhora cett.] padre mal hora $G^{3}$ 46 soltedes $c n$ hora mala $C M$ ] solteys muy en hora mala $F 9 m p$ solteis \{soltes $P$ ) padre en hora mala $P C 47$ que a no ser padre no hiziera $C$ ] que a non sello \{serlo $F 9\}$ non \{a no serlo no $m p$ \} fiziera cett. 48 de palabras $C]$ con palabras $F 9 m p$ de palabra $M$ con palabra $P G 49$ con la mano mesma \{misma $\left.C^{5} F 9 m p\right\} \alpha$ ] con mis propias manos $\beta 50$ vos cett.] os $m p 51$ faziendo cett.] hiçiendo $m p \mid$ el dedo $C$ ] mi dedo $F 9 m p$ mi braço $\beta 53$ Llorando de gozo el viejo $\alpha]$ El padre llora de gozo $\beta 54$ dixo $C G]$ dize $F S P M$ díjole $m p \mid$ Fijo cett. $]$ Hijo $m p M 56$ indinación $\left.C^{12} G M\right]$ indignacion $C^{5} F 9 P$ alteraçión $m p$ 5657 Esa fiereza \{firmeza $G^{2} M$ \} assegura / con abonada fiança / el agrauio a mi fecho / con $\{$ en $P C\}$ tu esfuerço y echo de armas $\{y$ hechos $\partial$ armas $P G\}$ om. $\alpha 57$ Estos braços $\left.C^{12}\right]$ Essos fieros $F^{9}$ Essos braços $C^{5}$ Esos brios $\beta m p$ 58 muéstralos en la demanda $\mathrm{Cmp}]$ teneldos en la vengança $F 9$ mostraldos en la vengança $M$ muestralos en la vengança $P G 59$ de mi honor que está perdido cett.] de mi honrra ques perdida $m p 60$ si en ti $C m p G M]$ si en vos $F 9$ sin ti $P \mid$ cobra y cett. $]$ cobra, o $C^{5} \mid$ gana $\left.C m p\right]$ halla cett. 61 su agravio cett. ] el agrabio $m p 62$ la espada cett. ] su espada $m p$ el espada $P 63$ dio al Conde la muerte $\alpha$ ] dio la muerte al Conde $\beta 64$ fazañas $C m p P G]$ hazañas $F 9$ azañas $M$ 
ERRORES DE IMPRENTA CORREGIDOS EN $C^{I 2}$

9 dormir ] darmir 14 la fabla ] lo fabla

HIPÓTESIS SOBRE LAS RELACIONES ENTRE TESTIMONIOS
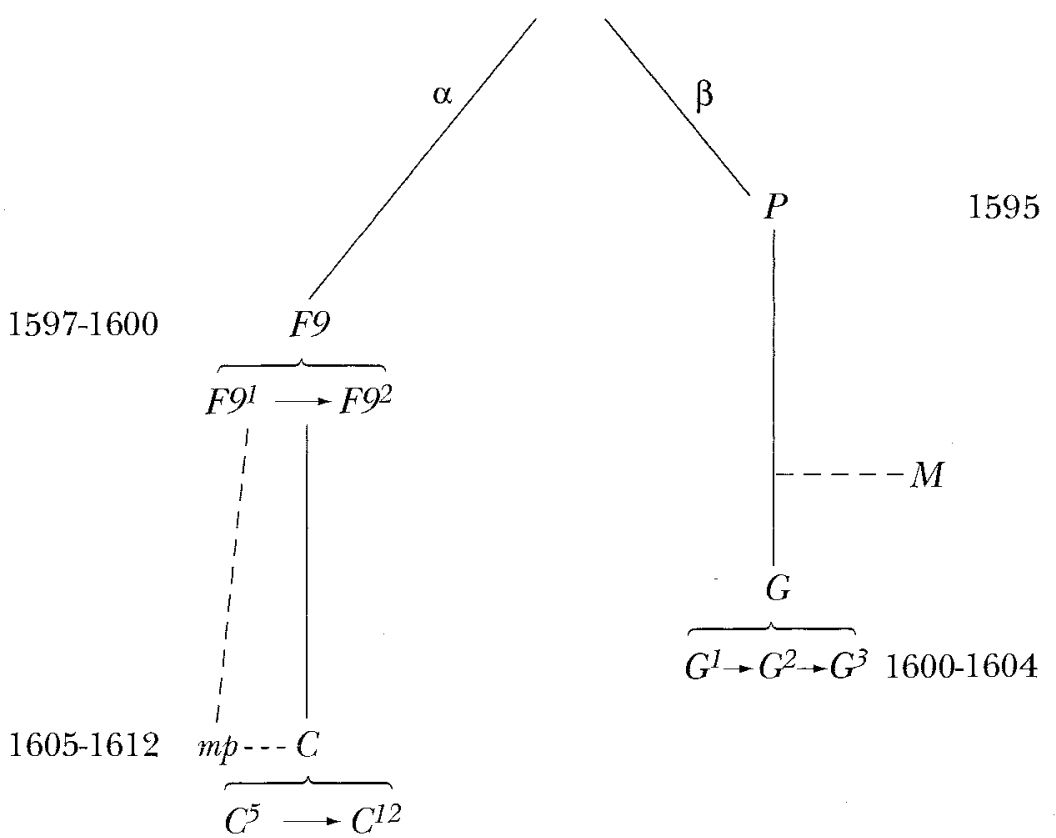